УДК 519.65

DOI https://doi.org/10.26661/2413-6549-2021-1-09

\title{
ЙМОВІРНІСТЬ: ВІД ПОЛІНОМІВ ЕРМІТА ДО КВАДРАТУРИ ГАУССА
}

\author{
Хомченко А. Н. \\ доктор фізико-математичних наук, професор, \\ професор кафедри інтелектуальних інформаційних систем \\ Чорноморський національний університет імені Петра Могили \\ вул. 68 Десантників, 10, Миколаїв, Україна \\ orcid.org/0000-0002-5053-388X \\ khan@chmnu.edu.ua \\ Литвиненко О. I. \\ кандидат технічних наук, дочент, \\ дочент кафедри інформаційних технологій та фізико-математичних дисииплін \\ Херсонська філія \\ Національного університету кораблебудування імені адмірала Макарова \\ пр. Ушакова, 44, Херсон, Украӥна \\ orcid.org/0000-0001-9890-6959 \\ mmkntu@gmail.com
}

\author{
Астіоненко I. O. \\ кандидат фізико-математичних наук, доиент, \\ доиент кафедри вищої математики і математичного моделювання \\ Херсонський національний технічний університет \\ Бериславське шосе, 24, Херсон, Украӥна \\ orcid.org/0000-0002-5831-6353 \\ astia@ukr.net
}

\begin{abstract}
Ключові слова: кусковолінійна інтерполяція, функиія«кришка», геометрична ймовірність, закон Ерміта розподілу ймовірностей, щиільність розподілу Ерміта, числові характеристики розподілу Ерміта, квадратурні правила Гаусса.
\end{abstract}

Стаття присвячена використанню ймовірнісних моделей у неймовірнісних задачах. Нові приклади, що наведені в роботі, допоможуть збільшити кількість прихильників рандомізації в математичному моделюванні. Розглядаються задачі відновлення фінітних функцій (функції-«кришки», функції Ерміта), які дуже поширені в методі скінченних елементів (MCE). Функція-«кришка» - це інша назва барицентричної координати, запропонованої Мьобіусом. На відміну від інтерполяції за Лагранжем, інтерполяція за Ермітом передбачає наявність у вершинах контрольного інтервалу інформації про функцію та їі похідну. Зростаючі поліноми Ерміта на канонічних інтервалах $[0 ; 1]$ i $[-1 ; 1]$ розглядаються як функції розподілу ймовірностей. Порівнюються два методи побудови поліномів Ерміта: традиційний (матричний) i нетрадиційний (ймовірнісний). Показано, що щільність i середнє квадратичне відхилення закону розподілу ймовірностей Ерміта мають тісний зв'язок із формулами наближеного інтегрування (квадратурами) підвищеної точності: ГауссаБернуллі (два вузли на $[0 ; 1])$, Гаусса-Лежандра (два вузли на $[-1 ; 1]$ ), Гаусса-Лобатто (для чотирьох вузлів). Ці результати свідчать про наявність «зворотного руху» ідей і методів із теорії ймовірностей в інші математичні науки. На гостру необхідність «зворотного руху» неодноразово звертав увагу видатний український науковець, фахівець 3 теорії ймовірностей і випадкових процесів академік А.В. Скороход. Дуже 
важливо, щоб «зворотний рух» підтримували усі математики, як «ймовірнісники», так і «неймовірнісники» (термін А.В. Скорохода).

Отримані результати вже не вперше переконують, що геометрична ймовірність - це простий, наочний і дуже ефективний метод математичного моделювання. Не дивно, що сучасні інформаційні технології починаються 3 когнітивних моделей прикладної геометрії. Такі моделі, як правило, математично обгрунтовані і фізично адекватні.

\title{
PROBABILITY: FROM HERMITE POLYNOMIALS TO GAUSS QUADRATURE
}

\author{
Khomchenko A. N. \\ Doctor of Physical and Mathematical Sciences, Professor, \\ Professor at the Department of Intellectual Information Systems \\ Petro Mogyla Black Sea National University \\ 68 Desantnykiv str., 10, Mykolaiv, Ukraine \\ orcid.org/0000-0002-5053-388X \\ khan@chmnu.edu.ua
}

Lytvynenko O. I.

Ph.D., Associate Professor,

Associate Professor at the Department of Information Technologies and Physical

and Mathematical Disciplines

Kherson Branch

of the Admiral Makarov National University of Shipbuilding

Ushakov avenue, 44, Kherson, Ukraine

orcid.org/0000-0001-9890-6959

mmkntu@gmail.com

\author{
Astionenko I. O. \\ Ph.D., Associate Professor, \\ Associate Professor at the Department of Higher Mathematics and Mathematical Modelling \\ Kherson National Technical University \\ Berislavsky highway, 24, Kherson, Ukraine \\ orcid.org/0000-0002-5831-6353 \\ astia@ukr.net
}

Key words: piecewise-linear interpolation, "lid"-function, geometric probability, Hermite's law of probability distribution, Hermite's density of distribution, numerical characteristics of Hermite distribution, Gauss quadrature rules.
The article is devoted to the use of probabilistic models in improbabilistic problems. The new examples presented in the paper will help to increase the number of supporters of randomization in mathematical modeling. Problems of restoration of finite functions ("lids"-functions, Hermite functions), which are widespread in a method of finite elements (MFE) are considered in the work. The "lid"-function is another name for the barycentric coordinate proposed by Möbius. In contrast to Lagrange interpolation, Hermite interpolation provides for the presence of information about a function and its derivative at the apexes of the control interval. Increasing Hermite polynomials at canonical intervals $[0 ; 1]$ and $[-1 ; 1]$ are considered as functions of probability distribution. Two methods of constructing Hermite polynomials are compared: traditional (matrix) and non-traditional (probabilistic). It is shown that the density and average quadratic deviation of the Hermite probability distribution law are closely related to the formulas of approximate integration (quadratures) of enhanced accuracy: Gauss-Bernoulli (two nodes on [0;1]), Gauss-Legendre (two nodes on $[-1 ; 1]$ ), Gauss-Lobatto (for four nodes). These results indicate 
the presence of a "reverse movement" of ideas and methods from probability theory to other mathematical sciences. A prominent Ukrainian scientist, a specialist in probability theory and random processes, the academician A.V. Skorokhod has repeatedly drawn attention to the urgent need for "reverse movement". It is very important that the "reverse movement" was supported by all mathematicians, both "probabilists" and "non-probabilists" (A.V. Skorokhod's term).

It is not the first time that the obtained results convince that geometric probability is a simple, clear and very effective method of mathematical modeling. Not surprisingly modern information technologies begin with cognitive models of applied geometry. Such models are usually mathematically sound and physically adequate.

Вступ. Математична теорія ймовірностей вже 3 часів Пуассона, Лапласа і Гаусса використовує складний математичний апарат. Нині в публікаціях «ймовірнісників» трапляється практично увесь класичний математичний аналіз, включаючи теорію рівнянь з частинними похідними, а також апарат теорії міри та функціонального аналізу. Незважаючи на це, теорія ймовірностей довгий час не вважалася математичною наукою. Поступове визнання теорії ймовірностей як математичної науки почалося у 1933 році, коли A.M. Колмогоров опублікував у видавництві Шпрингера німецькою мовою статтю «Основні поняття теорії ймовірностей» 3 аксіоматичною побудовою цієї теорії.

Специфічність проблеми полягає в тому, що теорія ймовірностей виступає стосовно всієї іншої математики як споживач. А.В. Скороход звертає увагу науковців на відсутність зворотного руху плідних ідей і нових методів. У нашій роботі використовується ймовірнісна інтерпретація задач відновлення фінітних функцій, які дуже поширені в методі скінченних елементів (МСЕ). Базисні лінійні і кубічні поліноми розглядаються як закони розподілу ймовірностей. Це допомагає зрозуміти, що зворотний рух (на жаль, повільний) насправді існує, але інколи він проявляється найнесподіванішим чином.

Огляд літератури. Ретроспективний аналіз варто почати зі статті А.В. Скорохода, яка була опублікована у 1977 р. у журналі «У світі математики» [1]. Саме у цій роботі автор називає причини, які поділяють математиків на «ймовірнісників» і «неймовірнісників». Наполегливо та емоційно він пропонує ліквідувати напівнепроникну плівку, яка стримує зворотний рух ідей і методів.

На думку А.В. Скорохода, ця плівка знаходиться у свідомості математиків, які не знайомі навіть 3 азами теорії ймовірностей. Безумовно, ця стаття викликала певний резонанс. Невипадково професор математики Каліфорнійського університету (США) М. Шилінг надіслав свою статтю саме до редколегії журналу «У світі математики». Ця публікація у перекладі українською мовою вийшла у 2000 р. [2]. М. Шилінг підібрав приклади, які здатні якось заспокоїти прихиль- ників А.В. Скорохода і запевнити читачів, що зворотний рух відбувається. Нам також подобається ця тематика, ми слідкуємо за станом справ з 1982 р. [3]. Наші пошуки нових прикладів тривають [4; 5]. Тепер ми розглядаємо 3 ймовірнісної точки зору фінітні функції обчислювальної математики: функцію-«кришку», 3 якої почався розвиток МCE [6-8], і поліноми Ерміта, які успішно моделюють деформації згину пружних балок [9-11]. Варто відзначити, що ймовірність дає можливість не тільки знайти нову інтерпретацію поліномів, але і запропонувати новий (ймовірнісний) метод побудови цих поліномів (як за Лагранжем, так і за Ермітом). Розглядаючи поліноми як закони розподілу ймовірності випадкових величин і визначаючи числові характеристики цих законів, ми встановлюємо зв'язок ймовірності з квадратурами Гаусса. Корисно познайомитись 3 книгою [12], в якій є необхідна інформація і про поліноми Ерміта і про квадратури Гаусса. На жаль, деякі автори користуються поліномами Ерміта (які відомі вже 150 років), не посилаючись на Ерміта. Неприємно вражають автори $[6 ; 8]$ - співвітчизники видатного французького математика Ерміта. У роботі [8] поліном Ерміта називають поліномом Кунса. Це не зовсім правильно: заслуга Кунса у поширенні поліномів Ерміта на 2D-апроксимації (метод Кунса, 1966 р.).

Мета дослідження - за допомогою геометричної ймовірності сконструювати функцію-«кришку» (кусково-лінійний поліном) і функцію Ерміта (кусково-кубічний поліном); показати, що на канонічних інтервалах $[0 ; 1]$ i $[-1 ; 1]$ зростаючі поліноми мають всі властивості інтегральної функції розподілу ймовірностей; знайти ймовірнісний зміст та ймовірнісний розв'язок задачі про розташування вузлів на обчислювальних шаблонах квадратур Гаусса (за версіями Бернуллі, Лежандра, Лобатто).

Виклад основного матеріалу дослідження.

1. Ймовірність та кусково-лінійні базисні функиї в задачах інтерполящії.

Нехай функція $y=f(x)$ визначена на $[a, b]$. Введемо на $[a, b]$ сітку $a=x_{0}<x_{1}<\ldots<x_{n}=b$ i поставимо у відповідність кожному вузлу $i$ функцію $\phi_{i}(x)$ (рис. 1). 


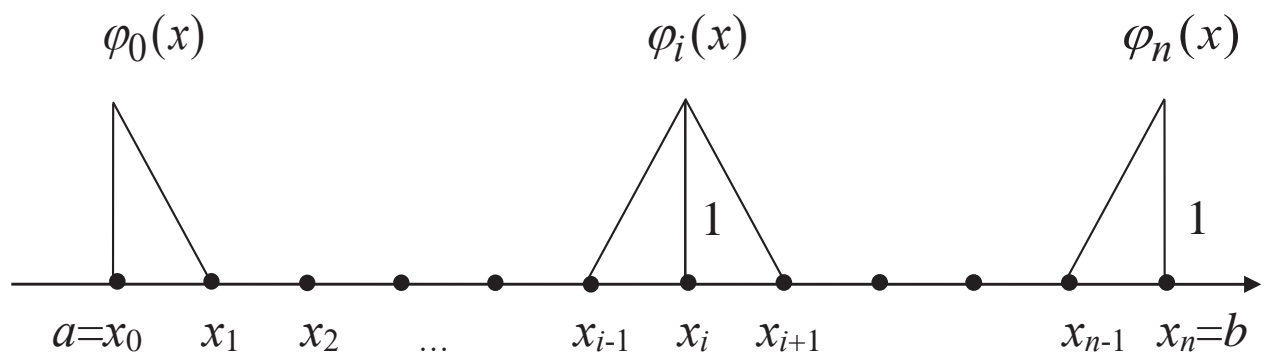

Рис. 1. Кусково-лінійні базисні функції

$$
\begin{gathered}
\phi_{i}(x)= \begin{cases}\frac{x-x_{i-1}}{x_{i}-x_{i-1}}, & x \in\left[x_{i-1}, x_{i}\right], \\
\frac{x_{i+1}-x}{x_{i+1}-x_{i}}, & x \in\left[x_{i}, x_{i+1}\right], \\
0, & x \notin\left[x_{i-1}, x_{i+1}\right] .\end{cases} \\
\phi_{0}(x)= \begin{cases}\frac{x_{1}-x}{x_{1}-x_{0}}, & x \in\left[x_{0}, x_{1}\right], \\
0, & x \notin\left[x_{0}, x_{1}\right] .\end{cases} \\
\phi_{n}(x)= \begin{cases}\frac{x-x_{n-1}}{x_{n}-x_{n-1}}, & x \in\left[x_{n-1}, x_{n}\right], \\
0, & x \notin\left[x_{n-1}, x_{n}\right] .\end{cases}
\end{gathered}
$$

У теорії інтерполяції функції-«кришки» відомі давно, але нова хвиля інтересу до них пов'язана із методом скінченних елементів [6-8]. Читачі, знайомі $з$ цим методом, впізнають (рис. 1) одновимірний аналог функції Куранта (1943р.).

Інтерполяційний поліном має вигляд:

$$
y=\sum_{i=0}^{n} \phi_{i}(x) \cdot f_{i},
$$

де $f_{i}$ - вузлові значення функції.

Головна перевага кусково-лінійної інтерполяції в тому, що зростаюча кількість вузлів не викликає небажаних осциляцій.

Ми шукаємо в кусково-лінійних функціях ймовірність. Звертаємо увагу, що всі функції (рис. 1) змінюються від 0 до 1. Кожна «кришка» накриває два одновимірні симплекси, або один, якщо це «напівкришка». Кожний симплекс має дві вершини i дві барицентричні координати. Термін «барицентричні» запропонував Мьобіус (1827р.). Функція-«кришка» - це інша назва барицентричної координати. Формули (1) здійснюють зв'язок декартової координати точки $x$ з барицентричними координатами цієї точки у відповідному симплексі. Таким чином, $\phi_{i}(x)$ - це ймовірність випадкового попадання у відрізок симплекса від точки $x$ до протилежної вершини симплекса $\left(x_{i-1}\right.$ або $\left.x_{i+1}\right)$. 3 точки зору теорії ймовірностей досить лишити тільки зростаючі «напівкришки», а у фор- мулах (1) замінити 0 на 1 на правому кінці відповідного симплекса. Саме так виглядає інтегральна форма (закон) рівномірного розподілу ймовірностей. Маючи на увазі квадратури Гаусса, нижче ми розглядаємо замість $[a ; b]$ канонічні інтервали $[0 ; 1]$ та $[-1 ; 1]$. Покажемо, як виглядають функції рівномірного розподілу на цих інтервалах. У теорії ймовірностей ці функції традиційно позначають через $F(x)$ :

$$
\begin{gathered}
F(x)= \begin{cases}0, & x<0, \\
x, & 0 \leq x \leq 1, \\
1, & x>1 ;\end{cases} \\
F(x)=\left\{\begin{array}{cc}
0, & x<-1, \\
\frac{1}{2}(x+1), & 0 \leq x \leq 1, \\
1, & x>1 .
\end{array}\right.
\end{gathered}
$$

Ці функції зображено на рис. 2.

Взагалі функція розподілу випадкової величини $X$ - це ймовірність влучення випадкової точки у «сприятливий» інтервал $F(x)=P(X<x)$. На рис. 2 «сприятливі» частини заштриховані.

2. Ймовірність та кубічні поліноми Ерміта.

На відміну від інтерполяції за Лагранжем, інтерполяція за Ермітом передбачає наявність у вершинах контрольного інтервалу інформації про функцію та іiі похідну. Таким чином, задача полягає у визначенні чотирьох коефіцієнтів кубічного полінома:

$$
F(x)=a_{0}+a_{1} x+a_{2} x^{2}+a_{3} x^{3} .
$$

Для цього формулюють інтерполяційну гіпотезу Ерміта (відповідні граничні умови). Наприклад, для зростаючого полінома на $[0 ; 1]$ граничні умови мають вигляд:

$$
\begin{aligned}
& F(0)=0, \quad F(1)=1, \\
& F^{\prime}(0)=0, \quad F^{\prime}(1)=0 .
\end{aligned}
$$

Граничні умови на $[-1 ; 1]$ відрізняються від (4) лише абсцисою на лівому кінці.

Таким чином, ми отримали функцію нерівномірного розподілу ймовірностей (закон Ерміта). Як бачимо, для побудови функції нерівномірного розподілу ймовірностей не досить знати іiі 

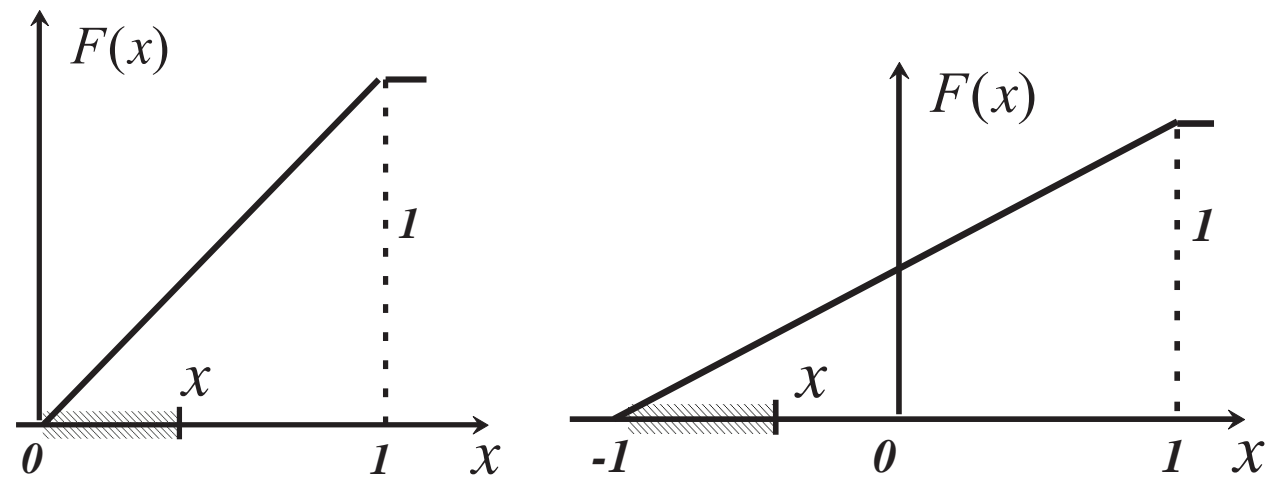

Рис. 2. Графіки функцій рівномірного розподілу випадкової величини в $[0 ; 1]$ та $[-1 ; 1]$
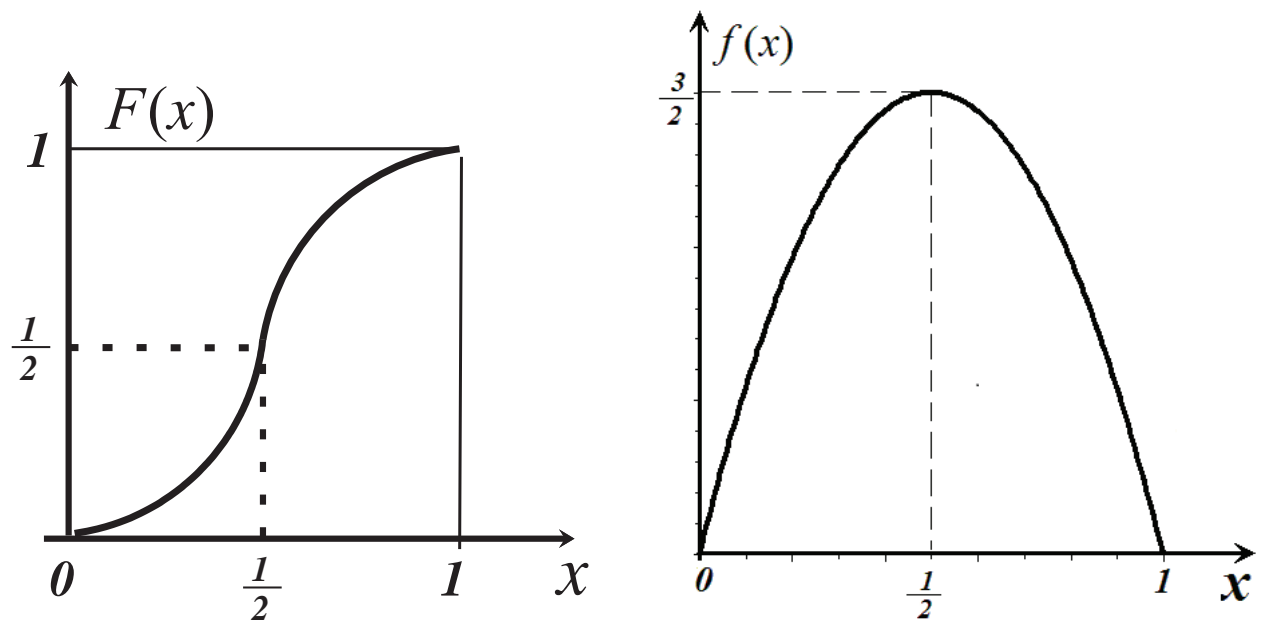

Рис. 3. Інтегральна та диференціальна функції розподілу ймовірностей (закон Ерміта)

граничні значення, потрібні додатково граничні значення щільності розподілу $f(x)=F^{\prime}(x)$. У деяких джерелах ці функції називають відповідно інтегральною і диференціальною. Опускаючи подробиці, запишемо результат матричного методу:

$$
\begin{aligned}
& \text { на }[0 ; 1] F(x)=-2 x^{3}+3 x^{2} ; f(x)=-6 x^{2}+6 x ; \\
& \text { на }[-1 ; 1] F(x)=\frac{1}{4}\left(-x^{3}+3 x+2\right) ; f(x)=\frac{1}{4}\left(-3 x^{2}+3\right) .
\end{aligned}
$$

Довжина канонічного інтервалу принципово не впливає на поведінку кубічних і квадратичних парабол (5). Тому на рис. 3 подано випадок $[0 ; 1]$.

У теорії ймовірностей закон Ерміта виглядає так:

$$
\begin{aligned}
\text { на }[0 ; 1] F(x) & = \begin{cases}0, & x<0, \\
-2 x^{3}+3 x^{2} & , x \in[0 ; 1], \\
1, & x>1 ;\end{cases} \\
f(x) & = \begin{cases}0, & x<0, \\
-6 x^{2}+6 x, & x \in[0 ; 1], \\
0, & x>1\end{cases}
\end{aligned}
$$$$
\text { на }[-1 ; 1] F(x)= \begin{cases}0, & x<0, \\ \frac{1}{4}\left(-x^{3}+3 x+2\right), x \in[-1 ; 1], \\ 1, & x>1 ;\end{cases}
$$

$$
f(x)=\left\{\begin{array}{l}
0, \quad x<-1, \\
\frac{3}{4}\left(-x^{2}+1\right), x \in[-1 ; 1], \\
0, \quad x>1 .
\end{array}\right.
$$

Уважний читач, мабуть, уже помітив, що закон Ерміта можна отримати, не користуючись матричною алгеброю. Враховуючи граничні умови і властивості щільності, отримаємо спочатку $f(x)$ . Після цього невизначеним інтегруванням відновлюємо $F(x)$. Нам подобається нематричний метод, в якому використовується добуток «напівкришок». Нагадаємо, що функція-«напівкришка» - це ймовірність. Тому йдеться про теорему множення ймовірностей. Дві «напівкришки» приховані у граничних умовах. Поліном $F(x)$ має двократний нуль на лівому кінці інтервалу. Третій нуль (простий) розташований за правим кінцем на 
відстані половини канонічного інтервалу. Таким чином, розглядається композиція із двох симплексів. Для випадку $[-1 ; 1]$ це показано на рис. 4.

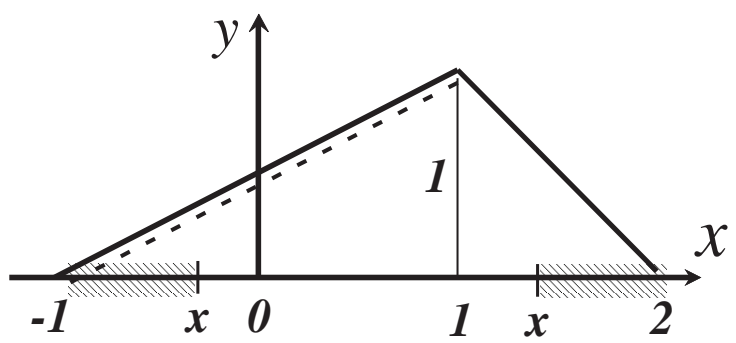

Рис. 4. Композиція «напівкришок» для $F(x)$ на $[-1 ; 1]$

Пунктирна пряма показує, що ліва «напівкришка» використовується двічі. Це означає, що у симплекс $[-1 ; 1]$ кидають навмання дві точки, а в симплекс $[1 ; 2]$ - одну. Ймовірність попадання двох точок у «сприятливий» інтервал $[-1 ; x]$ дорівнює $\left(\frac{x+1}{2}\right)^{2}$, ймовірність попадання точки в $[x ; 2]$ дорівнює $(2-x)$. Результат перемноження дає $F(x)=\frac{1}{4}\left(-x^{3}+3 x+2\right)$, щільність $f(x)=\frac{3}{4}\left(1-x^{2}\right)$. Аналогічна композиція на $[0 ; 1]$ дає відповідні формули (див. (5)). Математичне сподівання

$$
\begin{gathered}
M(X)=\int_{a}^{b} x \cdot f(x) d x ; \\
\text { для }[0 ; 1]-\text { це } \frac{1}{2}, \text { для }[-1 ; 1]-\text { це } 0 .
\end{gathered}
$$

Саме в цих точках $F(x)$ має перегин, а $f(x)$ максимум.

Сформулюємо задачу про щільність, яка дає несподівану можливість зробити крок із теорії ймовірностей у чисельні методи, а саме до квадратур Гаусса.

3. Задача про щільність розподілу ймовірностей (від Ерміта до Гаусса).

Нехай випадкова величина $X$ розподілена за законом Ерміта. Знайти на канонічному інтервалі точки, в яких щільність нерівномірного розподілу співпадає із щільністю рівномірного розподілу ймовірностей.

Для $[0 ; 1]$ маємо рівняння $-6 x^{2}+6 x=1$, звідки $x_{1,2}=\frac{1}{2} \pm \frac{\sqrt{3}}{6}$. Це нулі відомого рівняння Бернуллі другого порядку. Саме в цих точках Гаусс розта- шував вузли квадратури найвищої алгебраїчної точності.

Для $[-1 ; 1]$ маємо рівняння $\frac{3}{4}\left(-x^{2}+1\right)=\frac{1}{2}$, звідки $x_{1,2}= \pm \frac{1}{\sqrt{3}}$. Це нулі відомого рівняння Лежандра другого порядку. $\begin{array}{ll}\text { Квадратура Гаусса-Бернуллі: } & \int_{0}^{1} \phi(x) d x \approx \\ \approx \frac{1}{2}\left(\phi\left(x_{1}\right)+\phi\left(x_{2}\right)\right), & \int^{1} \phi(x) d x \approx\end{array}$

квадратура
$\phi\left(x_{1}\right)+\phi\left(x_{2}\right)$

Квадратура Гаусса-Лобатто визначається через дисперсію (точніше, через середнє квадратичне відхилення) закону Ерміта:

$$
D(X)=\int_{0}^{1} x^{2} \cdot f(x) d x-\frac{1}{4}=\frac{1}{20} ; \quad \sigma(X)=\frac{1}{2 \sqrt{5}} .
$$

Квадратура $є$ точною для многочленів степеня 5, має чотири вузли: два на кінцях інтервалу, іще два в точках:

$$
x_{1}=\frac{1}{2}-\frac{1}{2 \sqrt{5}} ; \quad x_{2}=\frac{1}{2}+\frac{1}{2 \sqrt{5}} .
$$

Обчислювальна формула Гаусса-Лобатто на $[0 ; 1]$ : $\int_{0}^{1} \phi(x) d x \approx \frac{1}{2}\left(\frac{1}{6} \cdot \phi(0)+\frac{5}{6} \cdot \phi\left(x_{1}\right)+\frac{5}{6} \cdot \phi\left(x_{2}\right)+\frac{1}{6} \cdot \phi(1)\right)$.

Для $[-1 ; 1]$ :

$$
D(X)=\int_{-1}^{1} x^{2} \cdot\left(-\frac{3}{4} x^{2}+\frac{3}{4}\right) d x=\frac{1}{5} ; \quad \sigma(X)=\frac{1}{\sqrt{5}} .
$$

Формула Гаусса-Лобатто:

$$
\int_{-1}^{1} \phi(x) d x \approx \frac{1}{6} \cdot \phi(-1)+\frac{5}{6} \cdot \phi\left(-\frac{1}{\sqrt{5}}\right)+\frac{5}{6} \cdot \phi\left(\frac{1}{\sqrt{5}}\right)+\frac{1}{6} \cdot \phi(1) .
$$

Як бачимо, це простіше і легше, ніж скласти i розв'язати систему нелінійних алгебраїчних рівнянь.

Висновки. Отримані результати вже не вперше переконують, що геометрична ймовірність - це простий, наочний і дуже ефективний метод математичного моделювання. Не дивно, що сучасні інформаційні технології починаються 3 когнітивних моделей прикладної геометрії. Такі моделі, як правило, математично обгрунтовані і фізично адекватні. На перспективу автори планують 3 ймовірнісної точки зору подивитися на поліном Ерміта п'ятого порядку $G(x)=6 x^{5}-15 x^{4}+10 x^{3}$, який має всі властивості закону нерівномірного розподілу ймовірностей. Здається, не всі цікаві властивості $G(x)$ нам відомі, хоча перший крок уже зроблено і зворотний рух триває.

\section{ЛІТЕРАТУРА}

1. Скороход А.В. Особливий характер теорії ймовірностей в математичних науках. У cвimi математики. 1997. Т. 3, вип. 2. С. 2-4. 
2. Шіллінг М. Ймовірність: від Монте-Карло до геометрії. У світі математики. 2000. Т. 6, вип. 3. C. $20-23$.

3. Хомченко А.Н. Некоторые вероятностные аспекты метода конечных элементов. Ивано-Франк. ин-т нефти и газа. 1982, 9 с. Деп. в ВИНИТИ 18.03.82 г. № 1213-82 Деп.

4. Хомченко А.Н., Литвиненко О.І., Астіоненко I.О. Ймовірнісні моделі у неймовірнісних задачах. Вісник Херсонського національного техн. університету. 2019. № 2 (69), ч. 3. С. 88-92.

5. Хомченко А.Н., Литвиненко O.I., Астіоненко I.O. Когнітивно-графічний аналіз ієрархічних базисів скінченних елементів : монографія. Херсон : ОЛДІ-плюс, 2019. 260 с.

6. Деклу Ж. Метод конечных элементов : монография. Москва : Мир, 1976. 95 с.

7. Марчук Г.И., Агошков В.И. Введение в проекционно-сеточные методы. Москва : Наука, 1981. 416 с.

8. Жермен-Лакур П., Жорж П.Л., Пистр Ф., Безье П. Математика и САПР: в двух кн. Кн. 2. Москва : Мир, 1989. 264 с.

9. Постнов В.А. Численные методы расчета судовых конструкций. Ленинград : Судостроение, 1977. 279 c.

10. Немчинов Ю.И. Расчет пространственных конструкций (метод конечных элементов). Киев : Будівельник, 1980. $231 \mathrm{c}$.

11. Астионенко И.А., Литвиненко Е.И., Хомченко А.Н. Когнитивно-графический анализ кривых Эрмита-Кунса пятого порядка. Системні технології. 2016. Вип. 3 (104). С. 73-78.

12. Мэтьюз Дж., Уокер Р. Математические методы физики. Москва : Атомиздат, 1972. 397 с.

\section{REFERENCES}

1. Skorokhod, A.V. (1997). Osoblyvyj kharakter teoriji jmovirnostej v matematychnykh naukakh. U sviti matematyky, 3, 2, pp. 2-4.

2. Shillingh, M. (2000). Jmovirnistj: vid Monte-Karlo do gheometriji. U sviti matematyky, 6, 3, pp. 20-23.

3. Khomchenko, A.N. (1982). Nekotorye veroyatnostnye aspekty metoda konechnykh elementov. IvanoFrank. in-t nefti i gaza. Dep. v VINITI 18.03.82 g. № 1213, 9 s.

4. Khomchenko, A.N., Lytvynenko, O.I., Astionenko, I.O. (2019). Jmovirnisni modeli u nejmovirnisnykh zadachakh. Visnyk Khersonsjkogho nacionaljnogho tekhn. universytetu, 2 (69), ch. 3, pp. 88-92.

5. Khomchenko, A.N., Lytvynenko, O.I., Astionenko, I.O. (2019). Koghnityvno-ghrafichnyj analiz ijerarkhichnykh bazysiv skinchennykh elementiv: monoghrafija. Kherson: OLDI-pljus.

6. Deklu, Zh. (1976). Metod konechnykh elementov: monografiya. Moscow: Mir.

7. Marchuk, G.I., Agoshkov, V.I. (1981). Vvedenie v proektsionno-setochnye metody. Moscow: Nauka.

8. Zhermen-Lakur, P., Zhorzh, P.L., Pistr, F., Bez'e, P. (1989). Matematika i SAPR: v dvukh kn. Kn. 2. Moscow: Mir.

9. Postnov, V.A. (1977). Chislennye metody rascheta sudovykh konstruktsiy. Leningrad: Sudostroenie.

10. Nemchinov, Yu.I. (1980). Raschet prostranstvennykh konstruktsiy (metod konechnykh elementov). Kiev: Budivel'nik.

11. Astionenko, I.A., Litvinenko, E.I., Khomchenko, A.N. (2016). Kognitivno-graficheskiy analiz krivykh Ermita-Kunsa pyatogo poryadka. Sistemni tekhnologiï, 3 (104), pp. 73-78.

12. Met'yuz, Dzh., Uoker, R. (1972). Matematicheskie metody fiziki. Moskva: Atomizdat. 